\title{
Book-to-Market, Size, and Industry Effect
}

\author{
Walid Saleh (Corresponding author) \\ Associate Professor of Corporate Finance, Arab Open University- Jordan Branch \\ Department of Business. P.O.Box 1339, Amman 11953 Jordan \\ Tel: 962-6-630-630Ｅ-mail: w_saleh@aou.edu.jo or wsaleh99@yahoo.com
}

\author{
Ayman Bitar \\ Assistant Professor of Financial Management \\ Petra University/Department of Banking \& Financing sciences \\ P.O.Box 961334 Amman 11196 Jordan
}

Tel: 962-7-7742-0662 Fax: 962-6-571-5570Ｅ-mail: akbitar@yahoo.com or abitar@uop.edu.jo

Received: August 10, 2010

Accepted: September 13, 2010

doi:10.5539/ijef.v3n2p263

\begin{abstract}
This paper aims to extend the paper by Saleh and Bitar (2009) by addressing whether variation in stock returns can be explained by differences in industry concentration. The paper concludes that firms operate in highly concentrated industries earn lower returns and less risk than those operate in highly competitive industries. Furthermore, the paper provides evidence to suggest that investors in Amman Stock Exchange cannot benefit from a trading strategy based on industry structure.
\end{abstract}

Keywords: Book-to-market effect, Size-effect, Industry Effect, Three-factor model

\section{JEL classification: G15}

\section{Introduction}

Porter (1980) provided a framework for classifying and analyzing industry structure. Porter's five forces framework views the profitability of an industry (measured by its rate of return) as determined by five sources of competitive pressure. These are: competition from substitutes, competition from entrants, competition from rivals, bargaining power of suppliers and bargaining power of buyers.

Recent research by Hou and Robinson (2006) tests the link between stock prices and market structure. The authors found that firms in highly concentrated industries earn lower return than those in highly competitive industries. They argued that "If barriers to entry in product markets insulate some firms from aggregate demand stocks, while exposing others, then we would expect distress risk to vary with market structure. This predicts that industries with high barriers to entry are associated with lower equilibrium stock returns. Thus, distress is another way that market structure can impact stock returns". Therefore, Hou and Robinson (2006) relied on the structure-conduct-performance approach in industrial organization to suggest that there are barriers to entry that restrict new firms from entering highly concentrated industries, thus, firms operate in these industries are able to exercise their power and earn abnormal returns which in turn lowers distress risk and returns.

This paper seeks to investigate how industry structure (concentration) contributes in explaining the variation in stock returns. Further, it aims to test the relationship between industry concentration and distress risk.

The main findings of the paper are: (1) firms operate in highly concentrated industries earn lower returns than those operating in highly competitive industries; (2) firms operate in highly concentrated industries face lower distress risk than those operating in highly competitive industries.

A major implication of this paper is that investors in Amman Stock Exchange can not benefit from an investment strategy of short and long positions based on the industry concentration indicators.

The remainder of the paper is organized as follows: Section 2 discusses the research hypothesis, Section 3 describes the empirical design and data, Section 4 presents the results and finally section 5 concludes.

\section{Research Hypotheses}

Theories of strategy addressed the question why firms within and between industries differ in their performance. One explanation of this question is that strategy is seen as primarily determined by the external conditions faced by 
the firm (e.g. Porter, 1980). This view is called the "competitive forces" approach to strategy. In this view, strategy is about the firm creating a market position for itself. For instance, the market positioning framework views differences between firms as resulting from the different characteristics of the markets they operate in. Imperfect competition is often blamed for not allowing all firms to achieve same level of efficiency and performance. Market imperfections such as barriers to entry prevent new firms from competing with incumbents. It is assumed that such differences will disappear in the long-run when perfect competition is restored.

Research in industrial organization was dominated by the linear "structure-conduct-performance" approach (SCP), which argues that it is the structure of an industry that determines the conduct of firms (e.g. their behavior regarding innovation, prices, advertising, etc.), which in turn determines their performance (e.g. market share and profits). The argument behind the SCP approach is on how market structure determines the attractiveness of an industry and hence how firms can position themselves in attractive industries when they can earn higher than average profits. For instance, the fewer firms there are in an industry (structure), the less price competition there is (conduct), hence the greater profits that can be made (performance).

Thus, firms exist in such markets are able to exercise their power and earn abnormal rents which in turn lowers returns. Hou and Robinson (2006) found that firms in highly concentrated industries earn lower returns. They indicated that stocks in the most competitive industries earn higher returns than those in the most concentrated industries.

Saleh and Bitar (2009) examined the relationship between book-to-market, size, and distress risk. They provided evidence suggesting that size and book-to-market effects are very important in estimating the risk premium in Amman Stock Exchange. Furthermore, they concluded that the distress risk is unlikely to account for the size and book-to-market effects (Note 1).

This paper aims to extend the paper by Saleh and Bitar (2009) by investigating the ability of industry effect (concentration) in explaining the variation in stock returns. Therefore, the paper seeks to test the following two hypotheses: firstly, firms operate in highly concentrated industries earn lower return than those operate in highly competitive industries. Secondly, firms operate in highly concentrated industries face less distress risk than those operate in highly competitive industries.

\section{Data and Methodology}

Firms included in the paper are constructed from all nonfinancial Jordanian firms over the 1980-2002 period. The paper uses three-month Treasury bill rates as a proxy for risk-free rates of return and monthly returns on the Amman Stock Exchange (ASE) value-weighted index as a proxy for market returns.

The paper measures industry concentration using the Herfindahl-Hirschman index (HHI). It is calculated by squaring the market share of each firm competing in the market and then summing the resulting numbers. The HHI takes into account the relative size and distribution of the firms in a market and approaches to zero when a market consists of a large number of firms of relatively equal size (Note 2), that is:

$$
H H I_{j}=\sum_{i=1}^{N} s_{i j}^{2}
$$

where, $s_{i j}$ is the market share of firm $i$ in industry $j, \mathrm{~N}$ is the number of firms in the market. ${ }^{i=1}$ Also, note that the paper uses equity and total assets to compute market share (Note 3 ).

In order to investigate how industry structure contributes in explaining the variation in stock returns, the paper conducts a portfolio analysis approach. Thus, for each year stocks are sorted in an ascending order into three portfolios based on their book-to-market values. Then, the paper computes returns for each portfolio over one, two, three, four, and five-year period. Thus, the simple average returns over the five-year period are calculated. Furthermore, the paper calculates the average cumulative three-year and five-year returns with monthly compounding. To test the first hypothesis of the paper (firms operate in highly concentrated industries earn lower return than those operate in highly competitive industries), the paper uses a four-factor model to explain the difference in returns between the highest book-to-market stocks and the lowest book-to-market stocks. This model represents the Fama and French (1993) three-factor model augmented by the industry effect factor; the paper refers to such new factor as highly-concentrated-stocks minus highly-competitive-stocks (HMC); that is (Note 4):

$$
R_{j, t}-R_{f, t}=a_{j}+\beta_{j}\left(R_{m, t}-R_{f, t}\right)+s_{j} S M B+h_{j} H M L+c_{j} H M C+e_{j, t}
$$

Where $R_{j, t}$ is the monthly return for stock $j$ at period $t, R_{m, t}$ is the monthly market return at period $t, R_{f}$ is the monthly 3-month Treasury bill rate, $e_{j, t}$ is an error term and $t$ represents the appropriate period after portfolio formation. $S M B$ (small minus big) is the monthly difference between the average of the returns on the three 
small-stock portfolios $(\mathrm{S} / \mathrm{L}, \mathrm{S} / \mathrm{M}$, and $\mathrm{S} / \mathrm{H})$ and the average of the returns on the three big-stock portfolios $(\mathrm{B} / \mathrm{L}, \mathrm{B} / \mathrm{M}$, and $\mathrm{B} / \mathrm{H})$. HML is the monthly difference between the average of the returns of the two high book-to-market portfolios $(\mathrm{S} / \mathrm{H}$ and $\mathrm{B} / \mathrm{H})$ and the average of the returns on the two low-book-to-market portfolios $(\mathrm{S} / \mathrm{L}$ and $\mathrm{B} / \mathrm{L})$. HMC (Note 5) is the difference, each month, between the average of the returns on the two high-concentrated portfolios and the average of the returns on the two low-concentrated portfolios. Following Fama and French (1993) the paper tests whether the intercept in each of the regressions is equal to zero using a conventional $t$-statistics.

To test the second hypothesis of the paper (firms operate in highly concentrated industries face less distress risk than those operate in highly competitive industries), the paper proceeds as follows: for each year stocks are sorted in an ascending order onto three portfolios based on their HHI-score values. Then, the paper computes monthly returns for each portfolio over the 1980-2002 period. The paper uses Fama and French (1993) three-factor model to explain the difference in returns between the highest concentrated stocks and the lowest concentrated stocks, that is:

$$
R_{j, t}-R_{f, t}=a_{j}+\beta_{j}\left(R_{m, t}-R_{f, t}\right)+s_{j} S M B+h_{j} H M L+e_{j, t}
$$

The variable are defined as above. Furthermore, the paper allows for a potential distress effect in stock returns by constructing healthy-minus-unhealthy (hereafter, HMU) factor. Thus, the paper tests the relationship between industry concentration and distress risk by adding the HMU factor to the Fama-French three-factor model, that is (Note 6):

$$
R_{j, t}-R_{f, t}=a_{j}+\beta_{j}\left(R_{m, t}-R_{f, t}\right)+s_{j} S M B+h_{j} H M L+z_{j} H M U+e_{j, t}
$$

The variables are defined as above, except that stocks are sorted based on HHI-score values in equation (4), whilst they were sorted based on book-to-market values in equation (2). HMU is the difference, each month, between the average of the returns on the two high-distress risk portfolios and the average of the returns on the two low-distress risk portfolios. To construct such a factor, the paper proceeds as follows: At the end of April of each year $\mathrm{t}$ stocks are allocated into two groups (big and small) based on whether their market value is above or below the median of the market. Furthermore, stocks are allocated in an independent sort to three Z-score groups (high, medium, and low) based on the breakpoints for the top 30\%, middle $40 \%$, and bottom $30 \%$ of the Z-score values. Following Fama and French (1993), the paper tests whether the intercept in each of the regressions is equal to zero using a conventional t-statistic.

\section{Empirical Results}

\subsection{Summary Descriptive Statistics}

Descriptive statistics of the test variables are presented in Table 1. Panel A of Table 1 shows mean and standard deviation of the test variables. Panel B of Table 1 presents the correlation coefficients. The correlation between HMC-sales, HMC-equity, and HMC-assets is positive and high. Note that this result is expected since all of them measure the degree of industry concentration.

Panel A of Table 2 reports the returns for portfolios formed based on book-to-market ratio. Overall, the results suggest that high book-to-market stocks do not outperform low book-to-market stocks. Panels B to D of Table 2 present the returns for portfolios formed based on HHI-score values where sales, assets, and equity are used as measures of industry concentration, respectively. Overall, the results suggest that highly concentrated stocks earn lower returns than highly competitive stocks.

\subsection{Industry Effect}

This sub-section aims to investigate the effect of industry structure on book-to-market and size effects.

Table 3 presents the results of a four-factor model (Fama-French's three-factor model augmented by the industry effect). Three measures of industry effect are used in this paper: sales, equity and total assets; Panels A to C of Table 3 , respectively.

To examine whether the four-factor model can explain the difference in returns between the highest book-to-market stocks and the lowest book-to-market stocks, the paper tests whether the intercept in each of the regressions is equal to zero using a conventional t-statistic.

Panel A of Table 3 presents the results of the four-factor model when the paper uses sales as a measure of industry concentration. The results show that the values of the estimated intercepts are not significant. The values of the beta coefficient for the hedge portfolio are not significant. Thus, the difference in returns between the highest book-to-market stocks and the lowest book-to-market stocks can not be attributed to risk differences.

The loading of SMB factor is positive and significant. The loading of HML factor is negative (positive) and significant for the lowest (highest) book-to-market stocks. As expected, lower book-to-market stocks tend to 
produce a negative loading factor for the book-to-market factor, whilst higher book-to-market stocks tend to produce a positive loading factor for book-to-market factor. The above results suggest that SMB and HML factors captured some variation in stock returns that is missed by the market factor.

The loading of HMC factor (the industry effect) is negative and significant for the lowest and highest book-to-market stocks. These results confirm that firms operate in highly concentrated industries earn lower returns than those operate in highly competitive industries. However, for the hedge portfolio, the loading of the HMC factor is positive but marginally significant at 10 percent level.

Panel B of Table 3 presents the results of the four-factor model when the paper uses equity as a measure of industry concentration. Overall, the results from Panel B of Table 3 are similar to those of Panel A of Table 3, however, the loading of HMC factor for the hedge portfolio is negative and significant. Panel $\mathrm{C}$ of Table 3 presents the results of the four-factor model when the paper uses assets as a measure of industry concentration. Overall, the results from Panel C of Table 3 are similar to those of Panel A of Table 3, however, the loading of HMC factor for the hedge portfolio is not significant.

The values of adjusted $R^{2}$ for the four-factor model are $0.934,0.934$, and 0.933 for Panels A, B, and C, respectively. These results suggest that the four-factor model explains most of the variation in stock returns.

Panel A of table 4 presents the results of Fama-French three-factor model when the paper uses sales as a measure of industry concentration. The results show that the value of the estimated intercept is not significant for low-concentrated stocks, but significant for high-concentrated stocks. For the hedge portfolio the value of the estimated intercept is not significant. The value of the beta coefficient for the hedge portfolio is not significant, thus, the difference in returns between the highest concentrated stocks and the lowest concentrated stocks can not be attributed to risk differences.

The loading of SMB factor is positive and significant for the lowest concentrated stocks, however, for the highest concentrated stocks, the loading of SMB factor is not significant. Note that the loading of SMB for the hedge portfolio is negative and significant. The loading of HML factor is negative and significant for the individual portfolios, but not significant for the hedge portfolio. The above results suggest that SMB factor captured some variation in stock returns that is missed by the market factor.

Panel B of Table 4 shows the results of Fama-French three-factor model when the paper uses assets as a measure of industry concentration. The values of the estimated intercepts are not significant for the individual portfolios. And for the hedge portfolio. The values of the beta coefficient for the hedge portfolio is positive and significant. This result may suggest that the difference in returns between the highest concentrated stocks and the lowest concentrated stocks may be attributed to risk factor.

The loading of SMB and HML factors is similar to those results from Panel A of Table 4. Panel C of Table 4 presents the results of Fama-French three-factor model when the paper uses equity as a measure of industry concentration. Overall, the results from Panel C of Table 4 are similar to those from Panel B of Table 4. However, the loading of HML factor for the hedge portfolio is marginally significant at 10 percent level.

Panel A of Table 5 presents the results of the four-factor model when the paper uses sales as a measure of industry concentration. The results show that the loading of the distress risk factor is positive and significant for the lowest concentrated stocks, but not significant for the highest concentrated stocks. This may suggest that highly concentrated stock face less distress risk than highly competitive stocks. The loading of the distress risk factor is negative and significant. This result suggests that the distress risk factor captured some variation in stock returns that is missed by the market, SMB, and HML factors.

Overall, the results from Panels B and C of Table 5 are similar to those from Panel A of Table 5. Tracing the values of the adjusted $R^{2}$ values yields the conclusion that the four-factor model does a better job in explaining the variation in tock returns. For example, the adjusted $R^{2}$ values from Panel A to C of Table 4 are $0.627(0.567)$, $0.662(0.595)$, and $0.510(0.618)$ for the lowest (highest) concentrated stocks, whilst the corresponding figures from Panels A to C of Table 5 are 0.701 (0.565), 0.747 (0.594), and 0.540 (0.616). For the hedge portfolios, the values of the adjusted $R^{2}$ from Table 4 are $0.615,0.640$, and 0.465 , whilst the corresponding figures from Table 5 are 0.677 , 0.777 , and 0.502 . Such results suggest that the four-factor model does a better job in explaining the variation in stock returns.

\section{Summary and Conclusion}

Hou and Robinson (2006) investigated the link between stock prices and market structure. They provided evidence to suggest that firms in highly concentrated industries earn lower return than those in highly competitive industries. They relied on the structure-conduct-performance approach in industrial organization to suggest that there are 
barriers to entry that restrict new firms from entering highly concentrated industries, thus, firms operate in these industries are able to exercise their power and earn abnormal returns which in turn lowers distress risk and returns. Saleh and Bitar (2009) investigated the relationship between book-to-market, size, and distress risk. Consistent with Dechive (1998), they concluded that distress risk is unlikely to account for size and book-to-market effects.

The aim of this paper is to extend the paper of Saleh and Bitar (2009) by addressing whether the variation in stock returns can be explained by differences in industry concentration. Furthermore, the paper seeks to examine the relationship between industry concentration and distress risk.

The paper finds that investors cannot benefit from a trading strategy with a long position in high-concentrated stocks and a short position in low-concentrated stocks. Moreover, the paper provides evidence suggesting that firms operate in highly concentrated industries earn lower returns and face less distress risk than those operate in highly competitive industries.

\section{References}

Altman, E. I. (1968). Financial ratios, discriminant analysis and the prediction of corporate bankruptcy. Journal of Finance, Vol. 23, PP. 589-609. Doi:10.2307/2978933, http://dx.doi.org/10.2307/2978933 .

Dichev, I. (1998) Is the risk of bankruptcy a systematic risk? Journal of Finance, Vol. 53, PP. 1131-1147. Doi:10.1111/0022-1082.00046, http://dx.doi.org/10.1111/0022-1082.00046 .

Fama, E. and K. French. (1993). Common Risk Factors In The Returns On Stocks and Bonds. Journal of Financial Economics, Vol. 33, PP. 3-56.

Griffin, J.M., and M. L. Lemmon (2002). Book to market equity, distress risk and stock returns, Journal of Finance, Vol. 57, PP. 2317-2336. Doi:10.1111/1540-6261.00497, http://dx.doi.org/10.1111/1540-6261.00497

Hou, K and Robinson, D. (2006). Industry Concentration and Average Stock Returns. The Journal of Finance, Vol. 61, No. 4, PP. 1927-1956. Doi:10.1111/j.1540-6261.2006.00893x, http://dx.doi.org/10.1111/j.1540-6261.2006.00893x

Porter, M. E. (1980). Competitive Strategy: Techniques for Analyzing Industries and Firms. New York: Free Press and Macmillan.

Saleh, Walid and A. Bitar (2009). Book-to-Market, Size, and Distress Risk, Journal of US-China Public Administration, Vol. 6, No. 5, PP. 9-15.

White, H. (1980). A Heteroskedasticity-Consistent Covariance Matrix Estimator and a Direct Test for Heteroskedasticity, Econometrica, Vol. 48, 1980, pp. 817-838. Doi:10.2307/1912934, http://dx.doi.org/10.2307/1912934

\section{Notes}

Note 1. Note that there result is consistent with Dichev (1998) and Griffin and Lemmon (2002).

Note 2. Note that the HHI increases as the number of firms in the industry decreases and as the disparity in size between firms increases.

Note 3. Following Hou and Robinson (2006), the paper uses the average values of HHI over the past three years.

Note 4. Following Fama and French (1993) the mimicking portfolios for the size (SMB) and book-to-market (HML) factors are constructed as follows. At the end of April of each year $t$ stocks are allocated to two groups (big and small) based on whether their market values are above or below the median of the market. Moreover, stocks are allocated in an independent sort to three book-to-market groups (high, medium, and low) based on the breakpoints for the top 30 percent, middle 40 percent, and bottom 30 percent of the book-to-market values. Note that the fiscal year-end for all companies listed on Amman Stock Exchange is the end of December. Thus, the paper permits for four-month gap to ensure that the data is available at the formation date.

Note 5.To construct such a factor, the paper proceeds as follows: At the end of April of each year $t$ stocks are allocated into two groups (big and small) based on whether their market value is above or below the median of the market. Furthermore, stocks are allocated in an independent sort to three HHI-score groups (high, medium, and low) based on the breakpoints for the top 30\%, middle $40 \%$, and bottom $30 \%$ of the HHI-score values.

Note 6. Note that the paper uses Altman (1968) model to estimate the Z-score for each stock. 
Table 1. Summary descriptive statistics of models factors and Correlation Matrix

\begin{tabular}{|c|c|c|c|c|c|c|}
\hline \multicolumn{7}{|c|}{ Panel A : Summary descriptive statistics of models factors } \\
\hline & XMR & SMB & HML & HMC- sales & HMC-equity & HMC-assets \\
\hline Mean & -0.0001 & 0.0019 & -0.0201 & 0.31 & 0.04 & -0.27 \\
\hline Std dev & 0.0356 & 0.0578 & 0.0822 & 9.82 & 7.32 & 8.17 \\
\hline P-value & 0.005 & 0.008 & 0.012 & 0.014 & 0.010 & 0.012 \\
\hline \multicolumn{7}{|c|}{ Panel B : Correlation matrix } \\
\hline & XMR & SMB & HML & HMC-sales & HMC-equity & HMC-assets \\
\hline XMR & 1 & & & & & \\
\hline SMB & 0.049 & 1 & & & & \\
\hline HML & -0.193 & -0.326 & 1 & & & \\
\hline HMC-sales & -0.07 & -0.59 & 0.28 & 1 & & \\
\hline HMC- equity & 0.05 & -0.66 & 0.09 & 0.59 & 1 & \\
\hline HMC- assets & 0.13 & -0.80 & 0.27 & 0.75 & 0.80 & 1 \\
\hline
\end{tabular}

The sample includes all nonfinancial Jordanian firms listed in Amman Stock Exchange over the 1980-2002 period. XMR is the excess market return, SMB (small minus big) is the monthly difference between the average of the returns on the three small-stock portfolios ( $\mathrm{S} / \mathrm{L}, \mathrm{S} / \mathrm{M}$, and $\mathrm{S} / \mathrm{H})$ and the average of the returns on the three big-stock portfolios $(\mathrm{B} / \mathrm{L}, \mathrm{B} / \mathrm{M}$, and $\mathrm{B} / \mathrm{H})$. HML is the monthly difference between the average of the returns of the two high book-to-market portfolios $(\mathrm{S} / \mathrm{H}$ and $\mathrm{B} / \mathrm{H})$ and the average of the returns on the two low-book-to-market portfolios $(\mathrm{S} / \mathrm{L}$ and B/L). HMC-sales, HMC-equity, and HMC-assets represent the difference, each month, between the average of the returns on the two high-concentrated portfolios and the average of the returns on the two low-concentrated portfolios, when we use sales, equity, and total assets as a measure for market share, respectively. P-value is calculated with standard errors using White (1980). 
Table 2. Returns for Portfolios.

\begin{tabular}{|c|c|c|c|c|}
\hline \multicolumn{5}{|c|}{ Panel A: Portfolios Formed Based on Book-to-Market Ratio } \\
\hline & Low B/M & Medium B/M & High $\mathbf{B} / \mathbf{M}$ & High B/M - Low B/M \\
\hline $\mathbf{R 1}$ & 0.326 & 0.085 & -0.016 & -0.343 \\
\hline $\mathbf{R 2}$ & 0.188 & 0.183 & 0.166 & -0.022 \\
\hline $\mathbf{R 3}$ & 0.050 & 0.134 & 0.173 & 0.123 \\
\hline R4 & 0.102 & 0.091 & 0.085 & -0.017 \\
\hline R5 & 0.086 & 0.115 & 0.099 & 0.013 \\
\hline AR5 & 0.150 & 0.122 & 0.101 & -0.049 \\
\hline AR CR3 & 0.818 & 0.376 & 0.207 & -0.611 \\
\hline AR CR5 & 1.306 & 0.653 & 0.458 & -0.849 \\
\hline \multicolumn{5}{|c|}{ Panel B: Portfolios Formed Based on HHI-Score Values ( Sales as a measure of industry concentration) } \\
\hline & Low Concentrated & Medium Concentrated & High Concentrated & $\begin{array}{c}\text { High Concentrated- Low } \\
\text { Concentrated }\end{array}$ \\
\hline R1 & 0.10 & 0.10 & 0.13 & 0.03 \\
\hline $\mathbf{R 2}$ & 0.18 & 0.21 & 0.15 & -0.03 \\
\hline $\mathbf{R 3}$ & 0.10 & 0.13 & 0.09 & -0.01 \\
\hline R4 & 0.10 & 0.09 & 0.09 & -0.01 \\
\hline R5 & 0.13 & 0.09 & 0.10 & -0.03 \\
\hline AR5 & 0.10 & 0.10 & 0.13 & 0.03 \\
\hline AR CR3 & 0.40 & 0.43 & 0.34 & -0.06 \\
\hline AR CR5 & 0.75 & 0.79 & 0.54 & -0.21 \\
\hline \multicolumn{5}{|c|}{ Panel C: Portfolios Formed Based on HHI-Score Values ( Assets as a measure of industry concentration) } \\
\hline $\mathbf{R 1}$ & 0.11 & 0.15 & 0.09 & -0.02 \\
\hline $\mathbf{R 2}$ & 0.17 & 0.22 & 0.14 & -0.03 \\
\hline $\mathbf{R 3}$ & 0.15 & 0.09 & 0.10 & -0.06 \\
\hline R4 & 0.13 & 0.07 & 0.09 & -0.04 \\
\hline R5 & 0.16 & 0.07 & 0.08 & -0.08 \\
\hline AR5 & 0.11 & 0.15 & 0.09 & -0.02 \\
\hline AR CR3 & 0.43 & 0.48 & 0.28 & -0.15 \\
\hline AR CR5 & 0.84 & 0.77 & 0.48 & -0.36 \\
\hline \multicolumn{5}{|c|}{ Panel D: Portfolios Formed Based on HHI-Score Values ( Equity as a measure of industry concentration) } \\
\hline R1 & 0.10 & 0.15 & 0.11 & 0.01 \\
\hline $\mathbf{R 2}$ & 0.16 & 0.21 & 0.16 & -0.01 \\
\hline $\mathbf{R 3}$ & 0.14 & 0.08 & 0.11 & -0.03 \\
\hline R4 & 0.14 & 0.11 & 0.05 & -0.08 \\
\hline R5 & 0.17 & 0.08 & 0.08 & -0.09 \\
\hline AR5 & 0.10 & 0.15 & 0.11 & 0.01 \\
\hline AR CR3 & 0.41 & 0.45 & 0.34 & -0.07 \\
\hline AR CR5 & 0.82 & 0.73 & 0.55 & -0.27 \\
\hline
\end{tabular}

Note: Table-2 values represent mean one-to-five-year buy and hold returns for portfolios formed in April each year, based on book-to-market ratio and HHI-score values. The sample period is from 1980-2002. AR5 is the average return for R1 to R5. CR3 and CR5 are the three-year and five-year cumulative returns. 
Table 3. Test for Book-to-Market Effect-Control for Industry Effect

\begin{tabular}{|c|c|c|c|c|}
\hline \multicolumn{5}{|c|}{ Panel A: Using Sales to compute market share } \\
\hline & Low B/M & Medium B/M & High B/M & High $\mathbf{B} / \mathbf{M}-$ Low $B / M$ \\
\hline$a$ & 0.001 & -0.002 & 0.002 & 0.000 \\
\hline $\mathrm{t}(\mathrm{a})$ & 0.392 & -0.560 & 0.482 & 0.127 \\
\hline$\beta$ & 1.027 & 0.822 & 0.955 & -0.071 \\
\hline $\mathrm{t}(\beta)$ & 10.831 & 8.211 & 10.649 & -1.510 \\
\hline$S M B$ & 0.235 & 0.128 & 0.534 & 0.300 \\
\hline $\mathrm{t}(\mathrm{SMB})$ & 3.219 & 1.668 & 7.751 & 8.242 \\
\hline$H M L$ & -0.697 & -0.095 & 0.380 & 1.078 \\
\hline $\mathrm{t}(\mathrm{HML})$ & -16.007 & -2.067 & 9.219 & 49.525 \\
\hline HMC & -0.149 & -0.065 & -0.115 & 0.034 \\
\hline $\mathrm{t}(\mathrm{HMC})$ & -3.524 & -1.451 & -2.877 & 1.605 \\
\hline$R^{2}$ & 0.773 & 0.344 & 0.573 & 0.934 \\
\hline \multicolumn{5}{|c|}{ Panel B: Using Equity to compute market share } \\
\hline$a$ & 0.000 & -0.002 & 0.001 & 0.000 \\
\hline $\mathrm{t}(\mathrm{a})$ & 0.102 & -0.684 & 0.264 & 0.280 \\
\hline$\beta$ & 1.100 & 0.828 & 1.045 & -0.054 \\
\hline $\mathrm{t}(\beta)$ & 11.319 & 8.064 & 11.825 & -1.128 \\
\hline$S M B$ & 0.200 & 0.190 & 0.408 & 0.209 \\
\hline $\mathrm{t}(\mathrm{SMB})$ & 2.420 & 2.182 & 5.440 & 5.125 \\
\hline$H M L$ & -0.732 & -0.102 & 0.343 & 1.075 \\
\hline $\mathrm{t}(\mathrm{HML})$ & -16.649 & -2.199 & 8.574 & 49.501 \\
\hline HMC & -0.200 & 0.000 & -0.266 & -0.066 \\
\hline $\mathrm{t}(\mathrm{HMC})$ & -3.195 & -0.006 & -4.667 & -2.132 \\
\hline$R^{2}$ & 0.771 & 0.337 & 0.601 & 0.934 \\
\hline \multicolumn{5}{|c|}{ Panel C: Using Total Assets to compute market share } \\
\hline$a$ & 0.000 & -0.002 & 0.001 & 0.00 \\
\hline $\mathrm{t}(\mathrm{a})$ & 0.101 & -0.685 & 0.263 & 0.266 \\
\hline$\beta$ & 1.132 & 0.841 & 1.056 & -0.076 \\
\hline $\mathrm{t}(\beta)$ & 12.596 & 8.255 & 12.683 & -1.574 \\
\hline$S M B$ & -0.077 & 0.127 & 0.198 & 0.276 \\
\hline $\mathrm{t}(\mathrm{SMB})$ & -0.850 & 1.227 & 2.352 & 5.640 \\
\hline HML & -0.700 & -0.100 & 0.381 & 1.081 \\
\hline $\mathrm{t}(\mathrm{HML})$ & -17.244 & -2.178 & 10.119 & 49.557 \\
\hline HMC & -0.406 & -0.057 & -0.399 & 0.008 \\
\hline $\mathrm{t}(\mathrm{HMC})$ & -6.378 & -0.789 & -6.755 & 0.223 \\
\hline$R^{2}$ & 0.801 & 0.339 & 0.642 & 0.933 \\
\hline
\end{tabular}

Note: At the end of April of each year $t$ stocks were sorted into two groups (small and big) based on whether their market capitalization is above or below the median of the market. Moreover, stocks were allocated in an independent sort to three book-to-market groups (high, medium, and low) based on the breakpoints for the top 30 per cent, middle 40 per cent, and bottom 30 per cent of the book-to-market values. From the intersection of the two size groups ( $\mathrm{S}$ and $\mathrm{B}$ ) and the three book-to-market groups ( $\mathrm{H}, \mathrm{M}$, and $\mathrm{L}$ ) six size-book-to-market portfolios were constructed.

$$
R_{j, t}-R_{f, t}=a_{j}+\beta_{j}\left(R_{m, t}-R_{f, t}\right)+s_{j} S M B+h_{j} H M L+c_{j} H M C+e_{j, t}
$$

Where, $R p-R_{f}$ is the individual portfolios return minus Treasury bill rate or the hedge portfolio return. SMB (small minus big) is the difference, each month, between the average of the returns on the three small-stock portfolios $(\mathrm{S} / \mathrm{L}, \mathrm{S} / \mathrm{M}$, and $\mathrm{S} / \mathrm{H})$ and the average of the returns on the three big-stock portfolios $(\mathrm{B} / \mathrm{L}, \mathrm{B} / \mathrm{M}$, and $\mathrm{B} / \mathrm{H})$. $\mathrm{HML}$ is the difference, each month, between the average of the returns of the two high-book-to-market portfolios $(\mathrm{S} / \mathrm{H}$ and $\mathrm{B} / \mathrm{H})$ and the average of the returns on the two low-book-to-market portfolios $(\mathrm{S} / \mathrm{L}$ and $\mathrm{B} / \mathrm{L})$. $\mathrm{HMC}$ is the difference, each month, between the average of the returns on the two high-concentrated portfolios and the average of the returns on the two low-concentrated portfolios. $\mathrm{t}\left(\right.$ ) is the t-statistic with standard errors calculated using White (1980). $R^{2}$ is adjusted for degree of freedom. 
Table 4. Test for Industry Effect-Control for risk using the Fama-French's Three-Factor Model

\begin{tabular}{|c|c|c|c|c|}
\hline \multicolumn{5}{|c|}{ Panel A: Using Sales to compute market share } \\
\hline & Low Concentrated & Medium Concentrated & High Concentrated & $\begin{array}{c}\text { High Concentrated-Low } \\
\text { Concentrated }\end{array}$ \\
\hline$a$ & 0.003 & 0.003 & 0.007 & 0.004 \\
\hline $\mathrm{t}(\mathrm{a})$ & 0.778 & 0.700 & 2.670 & 0.912 \\
\hline$\beta$ & 0.939 & 0.797 & 1.063 & 0.124 \\
\hline $\mathrm{t}(\beta)$ & 7.651 & 7.172 & 14.302 & 1.098 \\
\hline$S M B$ & 1.200 & 0.072 & -0.007 & -1.207 \\
\hline $\mathrm{t}(\mathrm{SMB})$ & 15.287 & 1.011 & -0.154 & -16.708 \\
\hline$H M L$ & -0.115 & -0.165 & -0.134 & -0.019 \\
\hline $\mathrm{t}(\mathrm{HML})$ & -2.045 & -3.254 & -3.933 & -0.366 \\
\hline$R^{2}$ & 0.657 & 0,287 & 0.567 & 0.615 \\
\hline \multicolumn{5}{|c|}{ Panel B: Using Equity to compute market share } \\
\hline$a$ & 0.003 & 0.007 & 0.003 & 0.000 \\
\hline $\mathrm{t}(\mathrm{a})$ & 0.792 & 1.683 & 1.317 & 0.019 \\
\hline $\boldsymbol{\beta}$ & 0.841 & 0.884 & 1.070 & 0.229 \\
\hline $\mathrm{t}(\beta)$ & 7.167 & 7.470 & 14.852 & 2.252 \\
\hline$S M B$ & 1.122 & 0.139 & 0.003 & -1.119 \\
\hline $\mathrm{t}(\mathrm{SMB})$ & 14.960 & 1.844 & 0.068 & -17.252 \\
\hline$H M L$ & -0.186 & -0.077 & -0.152 & 0.032 \\
\hline $\mathrm{t}(\mathrm{HML})$ & -3.438 & -1.420 & -4.622 & 0.696 \\
\hline$R^{2}$ & 0.688 & 0.277 & 0.601 & 0.646 \\
\hline \multicolumn{5}{|c|}{ Panel C: Using Total Assets to compute market share } \\
\hline$a$ & 0.004 & 0.005 & 0.005 & 0.000 \\
\hline $\mathrm{t}(\mathrm{a})$ & 0.947 & 1.031 & 1.699 & 0.070 \\
\hline$\beta$ & 0.839 & 0.802 & 1.143 & 0.304 \\
\hline $\mathrm{t}(\beta)$ & 6.733 & 6.031 & 15.447 & 2.743 \\
\hline$S M B$ & 0.851 & 0.425 & -0.038 & -0.889 \\
\hline $\mathrm{t}(\mathrm{SMB})$ & 10.692 & 4.999 & -0.793 & -12.526 \\
\hline$H M L$ & -0.088 & -0.135 & -0.181 & -0.093 \\
\hline $\mathrm{t}(\mathrm{HML})$ & -1.537 & -2.212 & -5.333 & -1.830 \\
\hline$R^{2}$ & 0.518 & 0.320 & 0.624 & 0.473 \\
\hline
\end{tabular}

Note: At the end of April of each year $t$ stocks were sorted into two groups (small and big) based on whether their market capitalization is above or below the median of the market. Moreover, stocks were allocated in an independent sort to three HHI-score values groups (high, medium, and low) based on the breakpoints for the top 30 per cent, middle 40 per cent, and bottom 30 per cent of the HHI-score values. From the intersection of the two size groups ( $\mathrm{S}$ and $\mathrm{B}$ ) and the three HHI-score values groups (H, M, and L) six size-HHI-score value portfolios were constructed.

$$
R_{j, t}-R_{f, t}=a_{j}+\beta_{j}\left(R_{m, t}-R_{f, t}\right)+s_{j} S M B+h_{j} H M L+e_{j, t}
$$

Where, $R p-R_{f}$ is the individual portfolios return minus Treasury bill rate or the hedge portfolio return. $S M B$ (small minus big) is the difference, each month, between the average of the returns on the three small-stock portfolios $(\mathrm{S} / \mathrm{L}, \mathrm{S} / \mathrm{M}$, and $\mathrm{S} / \mathrm{H})$ and the average of the returns on the three big-stock portfolios $(\mathrm{B} / \mathrm{L}, \mathrm{B} / \mathrm{M}$, and $\mathrm{B} / \mathrm{H})$. $\mathrm{HML}$ is the difference, each month, between the average of the returns of the two high-book-to-market portfolios $(\mathrm{S} / \mathrm{H}$ and $\mathrm{B} / \mathrm{H})$ and the average of the returns on the two low-book-to-market portfolios $(\mathrm{S} / \mathrm{L}$ and $\mathrm{B} / \mathrm{L})$. $\mathrm{t}(\mathrm{)})$ is the t-statistic with standard errors calculated using White (1980). $R^{2}$ is adjusted for degree of freedom. 
Table 5. Test for Industry Effect-Control for distress-risk Effect

\begin{tabular}{|c|c|c|c|c|}
\hline \multicolumn{5}{|c|}{ Panel A: Using Sales to compute market share } \\
\hline & Low Concentrated & Medium Concentrated & High Concentrated & $\begin{array}{c}\text { High Concentrated- Low } \\
\text { Concentrated }\end{array}$ \\
\hline$a$ & 0.001 & 0.001 & 0.007 & 0.006 \\
\hline $\mathrm{t}(\mathrm{a})$ & 0.295 & 0.305 & 2.678 & 1.603 \\
\hline$\beta$ & 0.985 & 0.831 & 1.062 & 0.076 \\
\hline $\mathrm{t}(\beta)$ & 8.571 & 7.783 & 14.206 & 0.735 \\
\hline$S M B$ & 1.108 & 0.004 & -0.004 & -1.112 \\
\hline $\mathrm{t}(\mathrm{SMB})$ & 14.716 & 0.064 & -0.086 & -16.377 \\
\hline$H M L$ & -0.017 & -0.094 & -0.137 & -0.120 \\
\hline $\mathrm{t}(\mathrm{HML})$ & -0.305 & -1.814 & -3.796 & -2.397 \\
\hline$H M U$ & 0.322 & 0.236 & -0.011 & -0.333 \\
\hline $\mathrm{t}(\mathrm{HMU})$ & 5.340 & 4.219 & -0.278 & -6.120 \\
\hline$R^{2}$ & 0.701 & 0.346 & 0.565 & 0.677 \\
\hline \multicolumn{5}{|c|}{ Panel B: Using Equity to compute market share } \\
\hline$a$ & 0.000 & 0.006 & 0.004 & 0.003 \\
\hline $\mathrm{t}(\mathrm{a})$ & 0.112 & 1.451 & 1.378 & 1.101 \\
\hline$\beta$ & 0.903 & 0.905 & 1.066 & 0.163 \\
\hline $\mathrm{t}(\beta)$ & 8.858 & 7.733 & 14.737 & 2.039 \\
\hline$S M B$ & 1.001 & 0.096 & 0.011 & -0.990 \\
\hline $\mathrm{t}(\mathrm{SMB})$ & 14.999 & 1.258 & 0.224 & -18.869 \\
\hline$H M L$ & -0.055 & -0.031 & -0.160 & -0.106 \\
\hline $\mathrm{t}(\mathrm{HML})$ & -1.112 & -0.548 & -4.585 & -2.725 \\
\hline$H M U$ & 0.427 & 0.151 & -0.026 & -0.454 \\
\hline $\mathrm{t}(\mathrm{HMU})$ & 7.991 & 2.456 & -0.691 & -10.784 \\
\hline$R^{2}$ & 0.747 & 0.285 & 0.594 & 0.777 \\
\hline \multicolumn{5}{|c|}{ Panel C: Using Total Assets to compute market share } \\
\hline$a$ & 0.003 & 0.003 & 0.004 & 0.002 \\
\hline $\mathrm{t}(\mathrm{a})$ & 0.609 & 0.634 & 1.653 & 0.458 \\
\hline$\beta$ & 0.872 & 0.845 & 1.145 & 0.273 \\
\hline $\mathrm{t}(\beta)$ & 7.204 & 6.635 & 15.392 & 2.543 \\
\hline$S M B$ & 0.785 & 0.341 & -0.041 & -0.827 \\
\hline $\mathrm{t}(\mathrm{SMB})$ & 9.912 & 4.093 & -0.848 & -11.757 \\
\hline HML & -0.017 & -0.045 & -0.176 & -0.159 \\
\hline $\mathrm{t}(\mathrm{HML})$ & -0.297 & -0.733 & -4.909 & -3.067 \\
\hline$H M U$ & 0.231 & 0.295 & 0.013 & -0.218 \\
\hline $\mathrm{t}(\mathrm{HMU})$ & 3.642 & 4.412 & 0.341 & -3.867 \\
\hline$R^{2}$ & 0.540 & 0.371 & 0.616 & 0.502 \\
\hline
\end{tabular}

Note: At the end of April of each year $t$ stocks were sorted into two groups (small and big) based on whether their market capitalization is above or below the median of the market. Moreover, stocks were allocated in an independent sort to three HHI-score value groups (high, medium, and low) based on the breakpoints for the top 30 per cent, middle 40 per cent, and bottom 30 per cent of the HHI-score values. From the intersection of the two size groups ( $\mathrm{S}$ and $\mathrm{B}$ ) and the three HHI-score values groups (H, M, and L) six size-HHI-score values portfolios were constructed.

$$
R_{j, t}-R_{f, t}=a_{j}+\beta_{j}\left(R_{m, t}-R_{f, t}\right)+s_{j} S M B+h_{j} H M L+z_{j} H M U+e_{j, t}
$$

Where, $R p-R_{f}$ is the individual portfolios return minus Treasury bill rate or the hedge portfolio return. SMB (small minus big) is the difference, each month, between the average of the returns on the three small-stock portfolios $(\mathrm{S} / \mathrm{L}, \mathrm{S} / \mathrm{M}$, and $\mathrm{S} / \mathrm{H})$ and the average of the returns on the three big-stock portfolios $(\mathrm{B} / \mathrm{L}, \mathrm{B} / \mathrm{M}$, and $\mathrm{B} / \mathrm{H})$. $\mathrm{HML}$ is the difference, each month, between the average of the returns of the two high-book-to-market portfolios $(\mathrm{S} / \mathrm{H}$ and $\mathrm{B} / \mathrm{H})$ and the average of the returns on the two low-book-to-market portfolios $(\mathrm{S} / \mathrm{L}$ and $\mathrm{B} / \mathrm{L})$. HMU is the difference, each month, between the average of the returns on the two high-distress risk portfolios and the average of the returns on the two low-distress risk portfolios. $\mathrm{t}(\mathrm{)})$ is the t-statistic with standard errors calculated using White (1980). $R^{2}$ is adjusted for degree of freedom. 